HISPANIA. Revista Española de Historia, 2010, vol. LXX, núm. 236, septiembre-diciembre, págs. 709-736, ISSN: 0018-2141

\title{
MEDICINA, ANTROPOLOGÍA Y ORDEN MORAL EN LA ESPAÑA DEL SIGLO XIX*
}

\author{
ENRIC J. NOVELLA \\ Centro de Ciencias Humanas y Sociales (CSIC), Madrid
}

RESUMEN: Partiendo de la idea de que el surgimiento de las modernas ciencias de la mente supone el resultado de un complejo proceso bistórico de constitución, secularización y naturalización del psiquismo, este artículo examina las condiciones para el despliegue de los discursos médico-psicológicos y la aparición de disciplinas como la medicina mental, la psicología experimental o las neurociencias en el contexto específico de la España del siglo XIX. Desde este punto de vista, y más allá de la recepción o asimilación de una serie de conceptos o prácticas concretas, el progresivo desarrollo del conocimiento médico del psiquismo aparece como un fenómeno articulado en torno a la influencia conjunta de tres factores igualmente relevantes: la paulatina implantación del proyecto ilustrado de naturalización del alma, la difusión de una nueva autocomprensión de la medicina como saber antropológico global y la aspiración de consolidar un determinado orden moral avalado por el prestigio y la autoridad de la ciencia en el marco de la nueva sociedad burguesa.

Palabras clave: Medicina. Antropología. Higiene. Pasiones. España. Siglo XIX.

\section{MEDICINE, ANTHROPOLOGY AND THE MORAL ORDER IN $19^{\mathrm{TH}}$ CENTURY SPAIN}

ABSTRACT: Based on the idea that the emergence of the modern sciences of mind is the result of a complex historical process of constitution, secularization and naturalization of the psyche, this article examines the conditions for the deployment of medicopsychological discourses and the origins of disciplines such as mental medicine, experimental psychology and neuroscience in the specific context of nineteenthcentury Spain. From this point of view, and going beyond the reception or

* Trabajo realizado en el marco del proyecto HAR 2008-04899-C02-01 (Ministerio de Ciencia e Innovación).

Enric J. Novella es investigador contratado (Programa JAE-Doc) del Centro de Ciencias Humanas y Sociales del CSIC (Grupo de Historia Social y Cultural de la Ciencia). Dirección para correspondencia: C/ Albasanz 26-28, 28037 Madrid (España).Correo electrónico: enric.novella@cchs.csic.es. 
assimilation of a series of concrete concepts or practices, the progressive development of the medical knowledge of the human psyche appears to have been largely stimulated by the joint influence of three equally important factors: the gradual introduction of the Enlightenment project of naturalizing the soul, the spreading of a new selfunderstanding of medicine as a global anthropological knowledge and the ambition of consolidating a certain moral order supported by the prestige and authority of science in the context of the new bourgeois society.

KEY WORDS: Medicine. Anthropology. Hygiene. Passions. Spain. 19th century.

«Ya podemos los médicos entregarnos sin reserva ni límite al anchuroso campo de nuestrasinvestigaciones para penetrar en el hondo abismo de las cuestiones psicológicas»

Juan Bautista Peset (1867)

\section{INTRODUCCIÓN}

En el primer capítulo de su Tratado teórico-práctico de frenopatología o estudio de las enfermedades mentales (1876), Juan Giné y Partagás, médico director del Manicomio Nueva Belén en las afueras de Barcelona, catedrático de su universidad y figura central en el proceso de institucionalización de la medicina mental española ${ }^{1}$, sostenía con orgullo que, en su opinión, existía una evidente «relación entre el progreso social y el de los conocimientos frenopáticos». Por ese motivo, Giné se felicitaba expresamente por haber dado a la imprenta el primer compendio español de la especialidad, glosando de forma entusiasta la aportación seminal de sus grandes pioneros europeos y, muy particularmente, la obra de P. Pinel:

«En el osado intento de Pinel vemos rielar el astro de la Medicina moderna, remontando su órbita de traslación hasta las regiones del mundo psicológico, para ejercitar un derecho que le atañe como ciencia biológica, experimental y curativa. De la obra de Pinel resultan a un tiempo: una adquisición moral de inestimable valor, y, para la medicina, una conquista de imponderable importancia. iCuánta gloria para un hombre!»².

Más allá del tono hagiográfico tan común en la retórica de la época, no deja de ser significativo que, en este párrafo introductorio, Giné reconozca justa-

1 Véanse, en este sentido, REY, Antonio, «Clásicos de la psiquiatría española del siglo XIX: Juan Giné y Partagás (1836-1903)», Revista de la Asociación Española de Neuropsiquiatría, 4 (1982), págs. 99-110; y HuERTAS, Rafael, Organizar y persuadir: Estrategias profesionales y retóricas de legitimación de la medicina mental española (1875-1936), Madrid, Frenia, 2002, págs. 82-96.

2 GINÉ y PARTAGás, Juan, Tratado teórico-práctico de frenopatología o estudio de las enfermedades mentales, Madrid, Moya y Plaza, 1876, pág. 2. 
mente en esa conquista del mundo psicológico el elemento verdaderamente constitutivo y singular del alienismo, y que, además, considere a éste como un particular «reflejo» del nuevo rumbo adquirido por la medicina con el advenimiento de la Modernidad. De este modo, su testimonio avala la apreciación de que la aparición del alienismo resulta inseparable de la conversión de la figura tradicional del loco en lo que podríamos denominar un sujeto psicológico y, en última instancia, de una progresiva incursión y apropiación discursiva del ámbito del psiquismo por parte de la medicina; pues, como él mismo sugiere, sólo una medicina abierta a la exploración sistemática del «mundo psicológico» en sus relaciones con la salud y la enfermedad pudo descubrir, validar y cultivar un ámbito propio en el psiquismo del loco y proceder así a una paulatina medicalización del mismo ${ }^{3}$.

Como es sabido, el interés de la medicina por la dimensión psíquica, anímica o espiritual de la naturaleza humana se remonta a la Antigüedad clásica, pero su inserción definitiva en el ámbito del saber propiamente médico constituye un acontecimiento que se deriva de los desplazamientos operados por el pensamiento antropológico de la Ilustración. Relegado por el galenismo a la periferia de la naturaleza enfermable y por la filosofía cartesiana a la esfera de una res cogitans transmundana y, por tanto, inaccesible al mecanicismo militante de la nuova scienza, el psiquismo devino un objeto de atención preferente por parte de la ciencia ilustrada, hasta el punto de que una de sus principales aspiraciones consistió justamente en la fundación de un conocimiento empírico o fisiológico del «hombre intelectual y moral» ${ }^{4}$. Del paradigma del «hombre máquina» a la noción de «hombre sensible», y de la consideración del individuo aislado al creciente interés por su entorno, la nueva fisiología vitalista y sensualista de la época basada en conceptos como la sensibilidad, la irritabilidad o la economía animalpermitió asimismo profundizar en el análisis de lo psíquico como un orden de factores tan capaces de influir en el estado del organismo como los propios eventos físicos 5 . Consecuentemente, algunas figuras señaladas de la medicina ilustrada

3 Esta perspectiva de análisis con respecto al nacimiento de la medicina mental ha sido desarrollada especialmente por SWAIN, Gladys, Le sujet de la folie: Naissance de la psychiatrie, Toulouse, Privat, 1977; pero se halla ya muy presente en la Historia de la locura de M. Foucault (Cf. FOUCAUlt, Michel, Historia de la locura en la época clásica, México DF, FCE, 1976, vol. II, págs. 190263). Véanse, asimismo, los trabajos de Goldstein, Jan, Console and Classify: The French psychiatric profession in the nineteenth century, Cambridge, Cambridge University Press, 1987; PORTER, Roy, Mind-Forg'd Manacles: A history of madness in England from the Restoration to the Regency, Cambridge MA, Harvard University Press, 1987; y Kaufmann, Doris, Aufklärung, Selbsterfahrung und die 'Erfindung' der Psychiatrie in Deutschland, 1770-1850, Gotinga, Vandenhoeck \& Ruprecht, 1995.

4 Véase MORAVIA, Sergio, "The Enlightenment and the sciences of man", History of Science, 18 (1980), págs. 247-268; WOKLER, Richard, "From 'l'homme physique' to 'l'homme moral' and back: Towards a history of Enlightenment anthropology", History of the Human Sciences, 6 (1997), págs. 121-138; o WolfF, Larry y Cipolloni, Marco (eds.), The Anthropology of the Enlightenment, Stanford CA, Stanford University Press, 2007.

5 Cf. Moravia, Sergio, "From 'homme machine' to 'homme sensible': Changing eighteenth century models of man's image", Journal of the History of Ideas, 39 (1978), 45-60; RoussEAU, George 
como G.E. Stahl, A. Le Camus o S.A.D. Tissot insistieron en el papel crucial de las pasiones o la imaginación en la génesis de las más diversas enfermedades, al tiempo que otros autores, como el escocés John Gregory en 1765, se lamentaban de la «indecible pérdida que supone para los médicos no haber tenido en cuenta, por lo general, las leyes peculiares de la mente y de su influencia sobre el cuerpo» ${ }^{6}$.

A finales del siglo XVIII, el estudio de las pasiones y otros fenómenos psíquicos se había convertido ya en un tópico sistemáticamente reivindicado por los médicos frente a las aportaciones de los filósofos o los moralistas, como prueban la memoria de William Falconer premiada en 1787 por la Medical Society de Londres, la monografía publicada en 1798 por el médico militar francés Clément-Joseph Tissot tras una convocatoria de la Académie Royale de Chirurgie de París o el influyente estudio de Sir Alexander Crichton sobre la naturaleza y las causas de la locura aparecido el mismo año ${ }^{7}$. Por lo demás, el rastro de esta naturalización del psiquismo acometida por la ciencia ilustrada y del énfasis de los médicos en su potencial patógeno puede seguirse en línea recta hasta las formulaciones de los primeros alienistas y, de hecho, explica el peculiar psicologismo organicista de que estos hicieron gala y los fundamentos mismos del tratamiento moral que otorgó carta de naturaleza a la nueva medicina mental. En este sentido, conviene recordar cómo el interés de los alienistas por la anatomía patológica o su creencia en el asiento visceral de la locura convivieron durante décadas con una elaborada tecnología de distracción, reeducación y manipulación carismática de las pasiones, pues, como apuntaba el joven Jean Étienne Dominique Esquirol en su tesis doctoral de 1805,

«(...) si las ideas, las afecciones morales, ejercen una influencia tan marcada sobre el organismo, ¿por qué negar tal influjo sobre la curación de una enfermedad que tan frecuentemente corresponde al sistema nervioso y cuya causa es la alteración de las funciones de dicho sistema?»8.

S. (ed.), The Languages of Psyche: Mind and body in Enlightenment thought, Berkeley, UCLA Press, 1991; o REY, Rosalyne, "L'âme, le corps et le vivant", en: GRMEK, Mirko (dir.), Histoire de la pensée médicale en Occident, vol. 2: De la Renaissance aux Lumières, París, Seuil, 1999, págs. 117-155.

6 Citado por Hunter, Richard y MacalPIne, Ida, Three Hundred Years of Psychiatry 15351860, Londres, Oxford University Press, 1963, pág. 438.

7 FAlCONER, William, A Dissertation on the Influence of the Passions upon Disorders of the Body, Londres, C. Dilly, 1788; Tissot, Clément-Joseph, De l'influence des passions de l'âme dans les maladies, París, Amand Koenig, 1798; y CRICHTON, Alexander, An Inquiry into the Nature and Origin of Mental Derangement: Comprehending a concise system of the physiology and pathology of the human mind and a history of the passions and their effects, Londres, Cadell JR and Davies, 1798. Para el conjunto del siglo XVIII, se han contabilizado no menos de doscientos estudios monográficos dedicados a las pasiones, a los que habría que sumar su tratamiento en la práctica totalidad de obras médicas generales y tratados de higiene de la época (Cf. MülLENER, Eduard Rudolf, "Die Rolle der 'Passions' in der Psychiatrie des 18. Jahrhunderts", en: BLASER, Robert y BUESS, Heinrich (eds.), Aktuelle Probleme aus der Geschichte der Medizin, Basilea, Karger, 1966, págs. 474-476).

8 Esquirol, Jean Etienne Dominique, Sobre las pasiones, Madrid, Asociación Española de Neuropsiquiatría, 2000, pág. 29, original de 1805. Véanse, en este sentido, los estudios de PIGEAUD, 
En cualquier caso, la paulatina inclusión del «mundo psicológico» entre los focos de interés y los ámbitos legítimos de intervención del médico ha de verse, asimismo, en el marco de las profundas transformaciones experimentadas por la medicina en el tránsito del siglo XVIII al XIX, que no sólo afectaron al alcance y la estructura epistémica del saber sobre la enfermedad, sino también a su proyección sociopolítica y a su propia autocomprensión como disciplina científica. Este proceso, que ha sido objeto de importantes estudios que muestran la estrecha interdependencia entre sus aspectos teóricos, institucionales y políticos ${ }^{9}$, culminó con la formulación de un ambicioso programa medicalizador cuyas implicaciones más sobresalientes han sido descritas con gran agudeza por Michel Foucault:

«En vez de permanecer como lo que era, el seco y triste análisis de millones de achaques, la dudosa negación de lo negativo, [la medicina] recibe la hermosa tarea de instaurar en la vida de los hombres las figuras positivas de la salud, de la virtud y de la felicidad. [...] No debe ser sólo el corpus de las técnicas de la curación y del saber que éstas requieren; desarrollará también un conocimiento del hombre saludable»10.

En Francia, el país en el que la «gran reforma» de la medicina tuvo inicialmente un protagonismo más evidente, este programa antropológico fue impulsado sobre todo por los miembros de la Escuela de Montpellier y los médicos vinculados a la Ideología. Influidos por los ideales ilustrados de unidad de las ciencias y de perfectibilidad del hombre, estos autores creían que el estudio del hombre, para ser completo, debía alimentarse de las contribuciones de las más diversas ciencias físicas y morales, pero reservando siempre a la medicina un lugar de privilegio en tanto «suprema ciencia del hombre vivo» ${ }^{11}$. Así, por

Jackie, «Le rôle des passions dans la pensée médicale de Pinel à Moreau de Tours», History and Philosophy of the Life Sciences, 2 (1980), págs. 123-140; o Huneman, Philippe, "Montpellier vitalism and the emergence of alienism in France (1750-1800): The case of the passions", Science in Context, 21 (2008), págs. 615-647.

9 Entre ellos cabe destacar Foucault, Michel, El nacimiento de la clínica: Una arqueología de la mirada médica, México DF, Siglo XXI, 1966; ACKerkneCht, Erwin H., Medicine at the Paris Hospital 1794-1848, Baltimore MD, The John Hopkins Press, 1967; y ARQUIOLA, Elvira y MonTIEL, Luis, La corona de las ciencias naturales: La medicina en el tránsito del siglo XVIII al XIX, Madrid, CSIC, 1993.

10 Foucault, Michel, El nacimiento..., págs. 60-61 (cursivas en el original). Véase también Foucault, Michel, «Historia de la medicalización», en: La vida de los hombres infames, Buenos Aires, Caronte, 1996, págs. 85-105.

11 La expresión procede de una conocida memoria presentada en 1799 a la Societé Médicale d'Emulation de París, en la que se compara la medicina con «aquellos ríos majestuosos que enriquecidos con el tributo de ajenas corrientes, por todas partes derraman la fecundidad, la esperanza y la felicidad» (ALIBERT, Jean Louis, Discurso sobre la conexión de la medicina con las ciencias físicas y morales o sobre los deberes, calidades y conocimientos del médico, Salamanca, Oficina de Francisco Toxar, 1803, pág. 4). 
ejemplo, P.J.G. Cabanis pensaba que sólo la medicina, una vez alcanzada su madurez por medio de la observación rigurosa de los fenómenos clínicos, la aplicación sistemática del método analítico y el estudio experimental de la fisiología, estaba en condiciones de liderar la nueva «ciencia del hombre» requerida por la sociedad posrevolucionaria, anticipando para ella «una nueva era tan rica en gloria como fecunda en beneficios» ${ }^{12}$.

Alentada por su creciente prestigio, y buscando extender su esfera de influencia hacia los territorios del buen gobierno y la administración de justicia, de la gestión de las poblaciones y la dirección de los individuos, del desarrollo físico, intelectual y moral o el cultivo de la virtud, la medicina europea entró pues en el siglo XIX con un ideario abiertamente expansionista e incluso utópico $^{13}$. El caso de la higiene, muy estudiado, es particularmente relevante en este contexto, pues fue la disciplina que, con su definitiva entrada en escena a finales del siglo XVIII y su gran pujanza posterior, mejor representó la ambición totalizadora e intervencionista de la nueva medicina. No en vano, el mismo Giné, que de forma simultánea al ejercicio privado de la medicina mental regentó entre 1868 y 1871 la cátedra de higiene de la Universidad de Barcelona y redactó un importante Curso elemental de higiene privada y pública (187172), llegó a definirla como «una verdadera Enciclopedia antropológica, encaminada a mejorar el bienestar físico y moral del hombre, en su existencia individual y en sus relaciones sociales» ${ }^{14}$. En estas coordenadas, no debe sorprender que el discurso médico en torno al psiquismo mantuviera durante buena parte del Ochocientos un tono eminentemente normativo y, salvo algunos casos aisla$\operatorname{dos}^{15}$, incluso una intención abiertamente moralizante, presentándose como un conjunto de prescripciones destinadas a estabilizar un determinado orden moral avalado por el marchamo científico de la medicina - y acorde con los valores de la emergente sociedad burguesa - . La extraordinaria popularidad de que

12 CaBAnis, Pierre-Jean-Georges, Coup d'oeil sur les révolutions et sur la réforme de la médecine, París, Crapelet, 1804, pág. 438. Sobre la enorme relevancia de la Escuela de Montpellier y los Ideólogos en la conformación de la medicina contemporánea pueden consultarse los trabajos ya clásicos de RosEN, George, "The philosophy of Ideology and the emergence of modern medicine in France", Bulletin of the History of Medicine, 20 (1946), págs. 328-339; MORAVIA, Sergio, "Philosophie et médecine en France à la fin du XVIIIe siècle», Studies on Voltaire and the Eighteenth Century, 39 (1972), págs. 1089-1151; y STAUM, Martin S., Cabanis: Enlightenment and medical philosophy in the French revolution, Princeton NJ, Princeton University Press, 1980; o el más reciente de WILLIAMS, Elisabeth A., The Physical and the Moral: Anthropology, physiology, and philosophical medicine in France, 1750-1850, Cambridge, Cambridge University Press, 1994.

13 Véase, en este sentido, SCHIPPERGES, Heinrich, Utopien der Medizin: Geschichte und Kritik der ärztlichen Ideologie des 19. Jabrbunderts, Salzburgo, Otto Müller Verlag, 1968.

14 Giné y PARTAgÁs, Juan, Curso elemental de higiene privada y pública, Barcelona, Imprenta de Narciso Ramírez, 1871, tomo 1: Higiene privada, pág. 9 (cursivas en el original).

15 Una notable excepción, en este sentido, es la contribución del médico escocés Alexander Crichton, tal como ha mostrado CHARLAND, Louis C., "Alexander Crichton on the psychopathology of the passions”, History of Psychiatry, 19 (2008), págs. 275-296. 
gozaron entonces las obras de higiene psíquica como la del austriaco Ernst von Feuchtersleben es muy indicativa de su amplia resonancia cultural en la Europa del siglo $\mathrm{XIX}^{16}$, pero también del planteamiento esencialmente higienizador que inspiró durante décadas el conocimiento médico del «hombre intelectual y moral».

Como parte de una serie de estudios dedicados a los aspectos teóricos, ideológicos y culturales relacionados con la emergencia y la difusión de las ciencias de la mente en la España del siglo XIX, el presente artículo tiene justamente por objeto reconstruir el despliegue de todo este proceso de apropiación discursiva del psiquismo por parte de los médicos españoles. Como es sabido, la limitada fragmentación y accidentada participación del país en las revoluciones burguesas del tránsito del siglo XVIII al XIX le impidió contribuir de forma activa y nuclear a la fijación de la orientación doctrinal y las líneas maestras de la ciencia y la medicina contemporáneas, de manera que éstas fueron inicialmente recibidas o asimiladas por parte de una reducida elite ${ }^{17}$. Sin embargo, y de forma paralela a la introducción de novedades concretas o la creciente influencia de especialidades tan representativas como la higiene, el alienismo o la medicina legal, algunos de los eventos más significativos del paulatino aggiornamento de la medicina española del siglo XIX fueron precisamente la generalización del mismo ideario naturalista, de la misma autocomprensión como saber antropológico y de la misma conciencia sociopolítica que la medicina europea exhibía desde finales del Setecientos. Desde este punto de vista, y como esperamos mostrar, el desarrollo del conocimiento médico del psiquismo y la implantación posterior de disciplinas como la medicina mental, la psicología experimental o las neurociencias —que sólo se completó en España en los años finales de la centuria- aparece como un complejo proceso que no sólo requirió la recepción y asimilación de una serie de conceptos y prácticas concretas, sino que se apoyó, ante todo, en una notable transformación de la comprensión que los médicos españoles - tanto como sus colegas europeos- tenían de su saber, de sus fines y de sus ámbitos legítimos de actuación.

16 De hecho, el original alemán de la obra de Feuchtersleben (Zur Diätetik der Seele, aparecida en 1838) tuvo no menos de 45 reediciones a lo largo del siglo XIX. Cf. GONZÁLEZ DE PABLO, Ángel, «El cuidado del cuerpo mediante el poder de la mente en la medicina romántica: la higiene mental de Ernst von Feuchtersleben (1806-1849)», en: MONTIEL, Luis y PORRAS, María Isabel (coords.), De la responsabilidad individual a la culpabilización de la víctima: el papel del paciente en la prevención de la enfermedad, Aranjuez, Doce Calles, 1997, págs. 67-88.

17 Para una visión panorámica de la evolución de la ciencia y la medicina españolas a lo largo del siglo XIX, véanse López Piñero, José M. ${ }^{a}$, García Ballester, Luis y Faus Sevilla, Pilar, Medicina y sociedad en la España del siglo XIX, Madrid, Sociedad de Estudios y Publicaciones, 1964; SÁnCHez Ron, José Manuel (ed.), Ciencia y sociedad en España: De la Ilustración a la Guerra Civil, Madrid, El Arquero-CSIC, 1988; o LÓPEZ PIÑERO, José M.a (ed.), La ciencia en la España del siglo XIX, Madrid, Marcial Pons, 1992 (Ayer, vol. 7). 


\section{LA NATURALIZACIÓN DEL ALMA}

En una sesión de la prestigiosa Sociedad de Medicina y demás Ciencias de Sevilla celebrada en 1788, el padre Fernando Valderrama abordaba desde el punto de vista de la «sublime Teología» la espinosa cuestión de «¿Si la Alma puede, y cómo causar enfermedades en el cuerpo humano?». Después de sostener que los «ángeles y espíritus réprobos $[\ldots .$.$] pueden mover y alterar nuestros sólidos y$ líquidos hasta hacernos enfermar, y aun morir», el autor pasaba a responder afirmativamente su pregunta de partida basándose en la consideración de las experiencias místicas — «que hacen padecer la Alma unos impulsos que debilitan la materia, o cuerpo, tanto más, cuanto el espíritu necesita más expurgación»-, para concluir confesando:

«Bien se hace cargo el autor de esta Memoria de lo intrincado, y casi impenetrable del argumento en cuestión, y que será quizá a muchos poco agradable su discusión; porque excede los límites de la Naturaleza: pero igualmente conoce, que en este sabio Ateneo han tenido muchas veces lugar varios discursos sobre milagros, que no menos salen de la esfera natural, pero no de la de este ilustrado Congreso» ${ }^{18}$.

Menos de un siglo después, el médico e higienista Benjamín de Céspedes disertaba en el Ateneo de Madrid sobre el Estudio fisiológico descriptivo de las pasiones humanas con la intención explícita de «sustituir a las causas ocultas y místicas, con ayuda de las cuales se explican los fenómenos morales, la exposición de las leyes físico-químicas, a los que aquellos son debidos». En plena eclosión del ideario positivista en la sociedad española de los primeros años de la Restauración, Céspedes afirmaba rotundamente y sin ambages que:

«(...) la investigación causal de las pasiones pertenece de derecho a la fisiología y el día que la ciencia diga su última palabra [...] el aéreo edificio levantado por filósofos y moralistas [...] se desvanecerá como el humo al potente grito de la ciencia, regenerando nuestra penalidad humana»19.

18 VAlderrama, Fernando, «iSi la alma puede, y cómo causar enfermedades en el cuerpo humano?», Memorias académicas de la Real Sociedad de Medicina y demás Ciencias de Sevilla, 6 (1788), págs. 258-281, págs. 267, 275 y 279-280. Sólo dos años antes, el presbítero y «socio de erudición» de la Academia Juan Carrasco había disertado nada menos que sobre «El poder del demonio en la parte física del hombre». Cf. Memorias académicas de la Real Sociedad de Medicina y demás Ciencias de Sevilla, 4 (1786), págs. 504-523.

19 CÉSPEDES, Benjamín, Estudio fisiológico descriptivo de las pasiones humanas, Madrid, Imprenta de la Viuda de García, 1876, págs. 3 y 23. El discurso de Céspedes se inspira abiertamente en los trabajos del médico y antropólogo materialista francés Charles Letourneau, particularmente Letourneau, Charles, Fisiología de las pasiones, Barcelona, Jané Hermanos, 1877 (original francés de 1868). Véanse, en una línea muy similar, CAMPO, Higinio del, «Sobre las pasiones», El Siglo Médico, 15 (1868), págs. 454-456 y 469-471; y VALLE Y HuERTA del, Gumersindo, Las pasiones ante las ciencias biológicas, Madrid, Imprenta de Enrique Teodoro, 1878. 
Más allá de la escasa entidad o influencia de sus autores en el contexto de su época, el abismo que media entre estos dos discursos académicos no puede resultar más indicativo de los profundos cambios implicados por el desarrollo de la aproximación al psiquismo característica de la ciencia moderna. Frente a la concepción tradicional del alma como una instancia espiritual vinculada a la intervención divina y a la economía del pecado y la salvación, el fundamento del estudio de las pasiones propuesto por Céspedes reside en la condición enteramente natural de los fenómenos psíquicos, que es en definitiva la que abre la posibilidad misma de su investigación «fisiológica» (esto es, con los medios de la ciencia natural) y «descriptiva» (o sea, exenta de consideraciones morales). Lógicamente, un desplazamiento epistémico y cultural de tal envergadura apunta a un proceso histórico de longue durée cuyos márgenes cronológicos resulta difícil determinar por la existencia de todo tipo de antecedentes, resistencias o posiciones intermedias. Pero, desde un punto de vista general, es indudable que la tendencia a naturalizar el alma o la conciencia supone una de las mutaciones más importantes producidas en la imagen del ser humano en el tránsito a la Modernidad, y ha de verse como el primer y más decisivo eslabón en la constitución histórica de las llamadas ciencias de la mente ${ }^{20}$.

Prescindiendo de sus precedentes en la obra de autores renacentistas como Juan Huarte de San Juan o Miguel Sabuco, el impulso más definido para la implantación en España de una concepción naturalista del psiquismo se debe, como en el resto de Europa, a la difusión de las corrientes del pensamiento y la ciencia de la Ilustración. Así, es bien conocida la progresiva influencia de la filosofía empirista y sensualista en los medios académicos españoles a partir de la segunda mitad del siglo XVIII ${ }^{21}$, y, más concretamente, la intensa recepción de la obra de Condillac y de los escritos de los Ideólogos franceses llevada a cabo entonces en algunos focos como la Universidad de Salamanca ${ }^{22}$. Un texto muy representativo que compendia y permite apreciar con claridad la implantación subsiguiente de los presupuestos naturalistas es, en este sentido, el in-

20 Sobre este punto pueden verse, por ejemplo, Porter, Roy, Flesh in the Age of Reason: The modern foundations of body and soul, Nueva York, Norton, 2003; MARTIN, Raymond y BARRESI, John, Naturalization of the Soul: Self and personal identity in the eighteenth century, Londres, Routledge, 2004; o VIDAL, Fernando, Les sciences de l'âme: XVIe-XVIIIe siècle, París, Champion, 2006.

21 Cf. SARRAilh, Jean, La España ilustrada de la segunda mitad del siglo XVIII, México DF, FCE, 1957, págs. 411-505; RODRígUEZ ARANDA, Luis, El desarrollo de la razón en la cultura española, Madrid, Aguilar, 1962, págs. 147-206; ABELLÁN, José Luis, Historia crítica del pensamiento español, vol. 3: Del Barroco a la Ilustración (Siglos XVII y XVIII), Madrid, Espasa-Calpe, 1981, págs. 512526; o MenÉndeZ-Pelayo, Marcelino, Historia de los heterodoxos españoles, Madrid, CSIC, 1992, vol. 2, págs. 712-789 (original de 1882).

22 Una relación exhaustiva de las numerosas traducciones españolas de las obras de estos autores se ofrece en GRACIA, Diego, «Ideología y ciencia clínica en España en la primera mitad del siglo XIX», Estudios de Historia Social, 12-13 (1980), págs. 229-243; y CASTRO AlfíN, Diego, «Los Ideólogos en España: La recepción de Destutt de Tracy y de Volney», Estudios de Historia Social, 36-37 (1986), págs. 337-343. 
forme redactado por una comisión de esta universidad sobre el Plan de Estudios presentado en 1814 a las Cortes de Cádiz por un grupo de diputados encabezados por Manuel José Quintana. Tras apuntar que «desde que Locke, Newton y Kant, guiados por el análisis, la analogía, y la experiencia, han abierto un camino tan seguro y dirigido con tanto acierto la marcha de las ciencias, sería una temeridad separarse de sus guías» ${ }^{23}$, el claustro de profesores salmantinos pasaba a proponer la creación de una asignatura de «fisiología o verdadera metafísica, o mas bien antropología» en la «carrera preliminar para todas las profesiones científicas» (equivalente a la educación secundaria), y describía del siguiente modo los contenidos de la misma:

«La fisiología es aquella parte de la metafísica que es única y verdaderamente útil, y se ocupa en el examen analítico de las facultades del alma, la parte física del origen de ellas y su descubrimiento, haciendo ver su esencial dependencia y maravillosa conexión con el cuerpo: el modo con que los órganos de éste, admirablemente construidos al intento, reciben las impresiones extrañas de las que resulta la sensación, y de ésta las ideas y todas las combinaciones que ponen en ejercicio la inteligencia del hombre, deduciéndose de aquí la justa idea que la razón puede formar del alma y de sus principales facultades» 24 .

Otorgando este papel central a una «fisiología» así entendida, la Universidad se proponía nada menos que reunir «las luces de los médicos al adelantamiento de los que cultivan las ciencias morales», porque — concluía— «¿quién ha desenvuelto la moral sino los conocimientos del hombre físico?» ${ }^{25}$.

Testimonios similares de la llegada a España del ideario naturalista de la antropología ilustrada pueden encontrarse, como cabría esperar, en numerosos textos médicos de esta época, vinculados casi siempre a la recepción de los planteamientos sensualistas, vitalistas o incluso materialistas de la medicina europea en el tránsito al siglo XIX. Un autor destacado, en este sentido, es el conocido bibliógrafo y polemista Bartolomé José Gallardo (1776-1852), que estudió medicina en Salamanca y redactó una serie de escritos en los que se han querido ver los orígenes mismos de la psicología fisiológica o las neurociencias en España ${ }^{26}$. A la pluma del joven Gallardo se deben las traducciones del Arte

23 Informe de la Universidad de Salamanca sobre el plan de estudios, Salamanca, Blanco, 1820, pág. XXII. El Informe, fechado originalmente el 25 de enero de 1814, no se pudo imprimir hasta 1820 debido a la restauración absolutista de 1814 .

24 Informe de la Universidad de Salamanca sobre..., págs. 56-57.

25 Informe de la Universidad de Salamanca sobre..., pág. XXI. Sobre la Escuela de Salamanca, ABellán, José Luis, Historia crítica del pensamiento español, vol. 4: Liberalismo y romanticismo (18081874), Madrid, Espasa-Calpe, 1984, págs. 55-76 y 181-203; y Heredia SorianO, Antonio, «La filosofía», en: JureTSCHKe, Hans (coord.), Historia de España Menéndez Pidal, vol. XXXV: La época del romanticismo (1808-1874), Madrid, Espasa-Calpe, 1989, págs. 329-420.

26 Así lo presentan, por ejemplo, NAVARRO, Jorge y GiSBERT, Juan, «La recepción del sensualismo en la España del siglo XIX. Un estudio histórico", Quaderns de Filosofia i Ciència, 8 
de conservar la salud y prolongar la vida (1800) de J.B. Pressavin y del ya citado Discurso sobre la conexión de la medicina con las ciencias físicas y morales (1803) de J.L. Alibert, así como las entradas «Sentidos» y «Sensaciones» del importante Diccionario de medicina y cirugía o biblioteca manual médico-práctica (1805-07) dirigido por Antonio Ballano. En un breve «Prólogo del traductor» al discurso de Alibert, Gallardo se muestra en total sintonía con los postulados de los Ideólogos cuando afirma que:

«las ciencias intelectuales y morales nada son sin el auxilio de la medicina. La moral no puede hacer adelantamientos sin que los haga antes la Ideología, y ésta no dará un paso si no se apoya en la Fisiología. Jamás se ha visto patente esta verdad, como ahora que se ha hecho casi de moda el estudio de la correlación del hombre físico y moral»27.

Por su parte, el artículo sobre las sensaciones del Diccionario de Ballano se abre con una referencia elogiosa a aquellos «talentos superiores [que han buscado] la verdad donde tiene su asiento, cimentando la Ideología sobre su única e invariable basa, el conocimiento del cuerpo humano», para pasar a exponer -remitiéndose en todo momento a los célebres Rapports du physique et du moral de l'bomme (1802) de Cabanis - el mecanismo diferencial de las sensaciones «externas e internas» que dan origen a la «totalidad de operaciones de nuestra alma» ${ }^{28}$. Es llamativo que, en este artículo, Gallardo cuestione incluso el sensualismo de Condillac basándose en la apreciación de que a éste «le faltaron tal vez algunos conocimientos más de la máquina animal» ${ }^{29}$, anticipando con ello la crítica que de sus remanentes espiritualistas vertería unas décadas después el médico Ramón Bercial. Bercial, una figura poco conocida pero de la que se sabe que estuvo vinculado a los ć́rculos masónicos afrancesados, publicó de hecho en 1838 un folleto inspirado abiertamente en el Système de la nature (1770) del Barón de Holbach en el que reprochaba a Condillac haberse detenido de forma inconsecuente ante las implicaciones materialistas de su sensua-

(1985), págs. 61-77; y NAVARRo, Jorge, «Bartolomé José Gallardo (1776-1852) y los orígenes de la psicología fisiológica en España», en: Actas del VIII Congreso Nacional de Historia de la Medicina. Murcia-Cartagena, 18-21 Diciembre 1986, Murcia, Universidad de Murcia, 1988, vol. 1, págs. 41-64. Sobre esta etapa y los escritos médicos de Gallardo es imprescindible consultar la espléndida monografía de PÉREZ VIDAL, Alejandro, Bartolomé J. Gallardo (Sátira, pensamiento y política), Mérida, Editora Regional de Extremadura, 1999, págs. 21-51.

27 ALIBERT, Jean Louis, Discurso sobre la conexión de la medicina..., pág. III.

28 Gallardo, Bartolomé José, «Sensaciones», en: Ballano, Antonio (dir.), Diccionario de medicina y cirugía o biblioteca manual médico-práctica, vol. 7, S-Z, Madrid, Imprenta Real, 1807, págs. 64-77, págs. 65 y 71.

29 GALLARDO, «Sensaciones»... En ese sentido, su artículo resulta más avanzado que la propia entrada Alma del Diccionario, que, con todo, se mueve netamente en las coordenadas del sensualismo condillaciano. Cf. BALlano, Antonio (dir.), Diccionario de medicina y cirugía o biblioteca manual médico-práctica, vol. 1, A-B, Madrid, Imprenta Real, 1805, págs. 150-156. 
lismo, y que, a pesar de su carácter marginal, resulta muy revelador de la paulatina progresión de las tesis naturalistas:

«No debe mostrarse orgulloso el hombre — afirmaba Bercial refiriéndose a la psicología- por la elevación que a su inteligencia ha concedido la naturaleza [...] bórrese para siempre toda idea de superioridad en su presuntuosa mente [...] pues todo es igual en el Universo. Todo obedece a unas mismas leyes» 30 .

Aparte del materialismo más o menos explícito de los Ideólogos, la presencia en la España de las primeras décadas del siglo XIX de otras doctrinas médico-psicológicas fuertemente organicistas como la «medicina fisiológica» del francés F.J.V. Broussais o la propia frenología constituye otro indicio directo de dicha progresión. Como es sabido, el brusismo contó en la península con una serie de expositores muy activos como el médico vallisoletano Manuel Hurtado de Mendoza (1783-1849), formado en París con Broussais y responsable de la traducción al castellano de sus principales obras. En el prólogo a una de ellas, por ejemplo, Hurtado lamentaba la irrupción de un nuevo «kanto-platonismo» que pretendía «disminuir el mérito de los pensamientos del siglo diez y ocho, y sustituir al estudio del hombre real, el del hombre ideal», avalando la intención de su maestro de «reclamar la psicología a favor de los fisiólogos, pues a éstos pertenece [...] el determinar lo que hay de apreciable en la causalidad de los fenómenos instintivos e intelectuales» ${ }^{31}$. En lo que respecta a la frenología, cabe señalar que la doctrina de F.-J. Gall —rápidamente secundada en Francia, entre otros, por el mismo Broussais - fue conocida en España mucho antes del intenso apostolado de Mariano Cubí y Soler (1801-1875) a partir de la década de 1840, habiendo aparecido en Madrid, en una fecha tan temprana como 1806, una primera completa «Exposición» de la misma ${ }^{32}$. Además, el descrédito posterior de las tesis frenológicas o la hostilidad que en su momento hubo de afrontar Cubí (que le llevó incluso a un sonado proceso ante el Tribunal Ecle-

30 Bercial, Ramón, Movimiento de la naturaleza, Madrid, Imprenta de Miguel Burgos, 1838, pág. 58. La aparición del folleto de Bercial provocó en su día un notable escándalo, hasta el punto de que la Gaceta de Madrid del 13 de abril de 1838 llegó a denunciarlo como un claro ejemplo de los riesgos de una «desenfrenada libertad de imprenta». Cf. CEPEDELlo BOISO, José, «Pensamiento político masónico, sensualismo y materialismo en la España decimonónica: La crítica de Ramón Bercial al espiritualismo de Condillac», Thémata, 40 (2008), págs. 11-29.

31 BroussaIs, François Joseph Victor, De la irritación y la locura, Madrid, Imprenta de García, 1828, págs. V-VI. Sobre la implantación del brusismo en España, véase MiQUEO, Consuelo, La introducción y difusión de la Médecine physiologique de F.J.V. Broussais (1772-1838) en España, Universidad de Zaragoza, Tesis doctoral, 1986.

32 Exposición de la doctrina del doctor Gall, o nueva teoría del cerebro considerado como residencia de las facultades intelectuales y morales del alma, Madrid, Imprenta de Villalpando, 1806. Véase Cf. BuJOSA, Francesc y MiQueO, Consuelo, «La prehistoria de la frenología en España», Medicina e Historia, 11 (1986), págs. 1-16. 
siástico de Santiago de Compostela ${ }^{33}$ ) no deben hacer olvidar que muchos médicos españoles, al menos inicialmente, acogieron de forma favorable las ideas de Gall — debido justamente a su supuesta fundamentación fisiológica-. Así lo veía, por ejemplo, el gaditano Francisco Javier Laso de la Vega, quien publicó en 1821 una amplia y elogiosa reseña de la edición francesa de la Anatomía y fisiología del sistema nervioso de Gall que concluía en los siguientes términos:

«Nos es grato pensar con el autor, que este estudio realizará un día las esperanzas que ha sugerido a los filósofos, y proporcionará nuevos medios de perfeccionar la filosofía moral, de mejorar la educación, en una palabra, de profundizar la ciencia del hombre, e ilustrar la filosofía racional por medio de la fisiología, que debe servirla de base» 34 .

En las décadas centrales del siglo XIX, y en medio de un repliegue generalizado de los moderados españoles hacia el espiritualismo filosófico ${ }^{35}$, la ambición de fundar el estudio del psiquismo sobre presupuestos estrictamente fisiológicos se mantuvo viva en la obra de algunas figuras aisladas pero de gran relieve como Pedro Mata (1811-1877). La gran proyección de Mata como catedrático, político y conferenciante es suficientemente conocida como para ser referida con detalle aquí, y lo mismo puede decirse de sus continuas diatribas contra la psicología espiritualista de su época. Sin embargo, sí es importante señalar que, sin que sus planteamientos se derivaran todavía de un compromiso explícito con la investigación de laboratorio, Mata hizo ya un notable esfuerzo por recurrir a observaciones fisiológicas concretas en apoyo de sus ideas — más próximas, en rigor, a un sensualismo impregnado de nominalismo que a un materialismo estricto- y de su intención de mostrar «el legítimo consorcio de la fisiología y de la psicología, o por mejor decir, la absorción natural de ésta por aquella» ${ }^{36}$.

33 La documentación de este proceso fue recogida posteriormente en Cubí y SOLER, Mariano, Polémica religioso-frenolójico-magnética sostenida ante el Tribunal Eclesiástico de Santiago, Madrid, Imprenta y Librería de José Tauló, 1848. Sobre Cubí, CARNICER, Ramón, Entre la ciencia y la magia: Mariano Cubí, Barcelona, Seix Barral, 1969; y Granjel, Luis S., La frenología en España (Vida y obra de Mariano Cubí), Salamanca, Ediciones Universidad de Salamanca, 1973.

${ }_{34}$ F.J.L., «Anatomía y fisiología del sistema nervioso en general y del cerebro en particular, por F.-J. Gall», Periódico de la Sociedad Médico-Quirúrgica de Cádiz, 2 (1821), págs. 86-93, pág. 93.

35 Cf. Heredia Soriano, Antonio, Política docente y filosofía oficial en la España del siglo XIX: La era isabelina (1833-1868), Salamanca, Instituto de Ciencias de la Educación, 1982; o NovelLA, Enric J., «La política del yo: Ciencia psicológica y subjetividad burguesa en la España del siglo XIX», Asclepio, en prensa.

36 Mata, Pedro, Filosofía española: Tratado de la razón humana con aplicación a la práctica del foro, Madrid, Carlos Bailly-Baillière, 1858, pág. VIII. Sobre la psicología en la obra de Mata, véase DOMÉNECH, Edelmira, «Las ideas de Pedro Mata en el campo de la psicología de su tiempo», Asclepio, 32 (1980), págs. 137-150; y LóPez FERnÁNDEZ, M. ${ }^{a}$ Nieves, La psicología en la obra de Pedro Mata y Fontanet, Valladolid, Universidad de Valladolid, 1993. Véase también la influyente apreciación de Mata por MenÉndez Pelayo, Marcelino, Historia de los heterodoxos..., págs. 1265-1269. 
Como ya se ha sugerido, la implantación definitiva de las modernas ciencias de la mente y, por tanto, la culminación de todo este proceso de naturalización del psiquismo, sólo pudo completarse en la España de la Restauración en el contexto del radical cambio de actitud hacia las aportaciones de la ciencia natural provocado por la irrupción del positivismo, el discurso regeneracionista y el despliegue de la cultura experimental ${ }^{37}$. A partir de ese momento, los hechos son conocidos: se consolida la institucionalización de la medicina mental; se difunden los métodos y resultados de la psicología experimental francesa y alemana; o se participa de forma muy destacada en el estudio histológico del sistema nervioso. En todas estas direcciones, son sobre todo médicos como Giné, Simarro o Cajal los que asumen el compromiso de contribuir al conocimiento-《fisiológico y descriptivo»- del hombre intelectual y moral, buscando materializar en la clínica o el laboratorio las viejas aspiraciones que los Ideólogos sólo pudieron consignar en sus escritos. Así, cuando Cajal inicie en 1899 la publicación de su Textura del sistema nervioso del hombre y de los vertebrados, presentará sus hallazgos en unos términos que resultan muy reveladores:

«Las teorías harto aventuradas, creadas menos por inspiración de los hechos que por imposición de ciencias forasteras [...] han cedido su lugar a otras más satisfactorias, surgidas del examen directo de la naturaleza, iluminada por el vivo resplandor de [...] métodos con los cuales el factor subjetivo, compañero inseparable de toda observación y origen de infinitos errores, queda reducido a un mínimo casi despreciable»38.

De todas formas, mucho antes de que esto ocurriese y de que dispusieran de un caudal apreciable de observaciones neuroanatómicas o psicofisiológicas consistentes, los médicos españoles ya habían dado por hecha la «conquista del mundo psicológico» de la que hablaba Giné, y la visión que tenían del lugar de su ciencia en el concierto de los saberes y en la regulación de los asuntos humanos había experimentado, como en otros países, un giro decisivo y radical.

\section{LA CIENCIA DEL HOMBRE}

En 1819, el médico e higienista liberal Mateo Seoane redactaba una sentida Carta exponiendo las verdaderas causas de la decadencia de la medicina en la que, aparte de denunciar las obsoletas estructuras administrativas de la asistencia

37 Cf. NúÑEZ RuIZ, Diego, La mentalidad positiva en España: Desarrollo y crisis, Madrid, Túcar, 1975; o BLANCO, Florentino y CASTRO, Jorge, «La significación cultural de la psicología en la España restaurada», en: JIMÉNEZ, Antonio, ORDEN, Rafael V. y AGENJO, Xavier (eds.), Nuevos estudios sobre historia del pensamiento español, Madrid, Fundación Ignacio Larramendi, 2005, págs. 293-307.

38 RAMÓN y CAJAL, Santiago, Textura del sistema nervioso del hombre y de los vertebrados, vol. 1, Madrid, Imprenta y Librería de Nicolás Moya, 1899, pág. VI. 
sanitaria en España, hacía un vívido retrato de las dificultades inherentes al ejercicio profesional de la medicina:

«Nadie puede dudar - decía Seoane- cuán doloroso debe ser para un hombre sensible el ejercicio de la ciencia de curar. El cuadro de las miserias humanas presente continuamente y bajo todos los aspectos, a su vista, es un fecundo manantial de sensaciones dolorosas para su corazón»39.

Un año después, el diputado y catedrático de la Universidad de Santiago José Francisco Vendrell de Pedralbes se dirigía a las Cortes en unos términos muy similares, añadiendo:

«¿Y será posible que unos individuos tan beneméritos, y consagrados al primero de los objetos por su importancia, al más arduo por sus dificultades y privaciones, al más triste por sus escenas y resultados, se hallen pospuestos y abatidos en España, en el siglo XIX que se jacta de ilustración y humanidad?»40.

Estos dos testimonios son muy representativos del sentir general de los médicos españoles durante las primeras décadas del siglo XIX, en las que hubieron de afrontar un verdadero "periodo de catástrofe» marcado por la guerra, la inestabilidad política y una crisis generalizada de las instituciones científicas y asistenciales del Antiguo Régimen. No obstante, la recepción de las principales corrientes y novedades de la medicina europea no llegó a detenerse gracias a las traducciones, la formación en el extranjero, los contactos académicos, la presencia francesa o el exilio de médicos liberales como el mismo Seoane ${ }^{41}$. De este modo, no sólo circularon doctrinas o prácticas concretas, sino que las elites liberales españolas empezaron a participar activamente de la nueva comprensión que de la medicina estaba germinando en otros países, y muy especialmente, del ideario antropológico esbozado para ella en la Francia del tránsito del siglo XVIII al XIX.

Muy vinculadas inicialmente a la asimilación de los escritos de los Ideólogos, las referencias a la medicina como ciencia del hombre (o como parte esencial de ésta) impregnan, de hecho, buena parte de los textos médicos españoles de la primera mitad del siglo XIX. A partir de ese momento, la medicina apa-

39 SEOANE, Mateo, «Carta exponiendo las verdaderas causas de la decadencia de la medicina», en: LÓPEZ-PIÑERO, José M. ${ }^{a}$, M. Seoane y la introducción en España del sistema sanitario liberal (17911870), Madrid, Ministerio de Sanidad y Consumo, 1984 (original de 1819), págs. 35-47, pág. 40.

40 PeDRAlBes, José Francisco, «Exposición del mérito y premio de la medicina comparado con el de las demás ciencias, y otros ramos del Estado, en el año de 1820», Décadas de Medicina y Cirugía Prácticas, 1 (1821), págs. 66-75 y págs. 68-69. Sobre la figura de Vendrell de Pedralbes y su destacada participación en los debates sanitarios del Trienio Liberal, véase CARDONA, Álvaro, «Los debates sobre salud pública en España durante el Trienio Liberal (1820-1823)», Asclepio, 57, 2 (2005), págs. 173-202.

41 Cf. LópeZ-PIÑERO, José M. ${ }^{a}$, «La comunicación con Europa en la medicina española del siglo XIX», Almena, 2 (1963), págs. 33-64. 
rece también en España —como bien señalaba Foucault- no sólo como la disciplina que compendia el saber sobre la enfermedad y sus técnicas de curación, sino como portadora y forjadora de un conocimiento positivo sobre el hombre que se pretende, además, omnicomprensivo. El mismo Vendrell de Pedralbes, por ejemplo, explicaba gráficamente en 1819 que: «el estudio, que el médico hace del hombre, no se limita al de sus músculos y entrañas; llega hasta el más completo análisis de su espíritu y su corazón. [...] Nada escapa a su ojo indagador» ${ }^{42}$. Sólo la medicina —afirmaba el conocido higienista Pedro Felipe Monlau en 1846- «comprende al hombre en todos sus pormenores, en toda su grandeza, en todos sus estados y en toda su verdad»43.

Ciertamente, los autores españoles no siempre secundaron el monismo fisiológico de un Cabanis o un Broussais para justificar esta nueva concepción de la medicina, y a menudo se limitaron a consignar fórmulas naturalistas bastante vagas o a insistir en la gran importancia del estudio médico de los fenómenos «intelectuales y morales» debido a su consabida influencia «sobre la parte física del hombre» ${ }^{44}$. Pero, en casi todos los casos, las referencias a la «ciencia del hombre» tenían por objeto avalar la extensión de la tutela de la medicina a la práctica totalidad de dimensiones de la vida individual y social. Así, el catedrático Ramón Frau y Armendáriz argumentaba sin esfuerzo en la apertura de las clases del Colegio Nacional de Medicina y Cirugía de San Carlos en 1842 que, dado que:

«la medicina es entre todas las ciencias la que se ocupa de una manera mas filosófica en el estudio del hombre físico, moral é intelectual [y queł la educación, la moral, la legislación y la administración del Estado [... ] no pueden cimentarse en otro principio ni tienen otra base sólida que el conocimiento del hombre», sólo la medicina podía considerarse como la «madre de aquellas ciencias, difundiendo sobre todas ellas rayos luminosos, que conducirán al hombre por el camino de la verdad y del acierto» ${ }^{45}$.

Por su parte, Mariano Delgrás, editor de un influyente semanario médico de la época, afirmaba en una de las sesiones inaugurales del Instituto Médico Español que:

42 Pedralbes, José Francisco, Influxo de las costumbres en el estudio y práctica de la medicina, Santiago de Compostela, Imprenta de Juan Bautista Moldes, 1819, pág. 4.

43 Monlau, Pedro F., Elementos de higiene privada, Barcelona, Imprenta de Pablo Riera, 1846, pág. 3 (cursivas mías, E.N.)

44 Véanse, por ejemplo, VARELA DE MONTES, José, «Fisiología filosófica», Boletín de Medicina, Cirugía y Farmacia, 4 (1837), págs. 109-13 y 121-5; o DÁvILA, Manuel H., Memoria sobre la naturaleza del hombre, Salamanca, Imprenta de Juan José Morán, 1845.

45 FRAU Y ARMENDÁRIZ, Ramón, La medicina es entre todas las ciencias la que se ocupa más filosóficamente en el estudio del hombre físico, moral e intelectual, Madrid, Imprenta de Alegría y Charlain, 1842, págs. 7-8. 
«apenas hay una cuestión social de grande o pequeña esfera que para su resolución no necesite de los conocimientos que sólo el médico posee por principios; porque $[. .$.$] en todas las cuestiones que se refieren al hombre, debe tomarse por$ base el conocimiento físico y moral de este mismo ser» ${ }^{46}$.

Más allá del notable impulso experimentado por la higiene o de la aparición de algunas obras con vocación enciclopédica como el Ensayo de antropología (1844-45) de José Varela de Montes ${ }^{47}$, la paulatina difusión de este ideario dio lugar al cultivo de toda una serie de géneros, muy característicos de la producción médica de la época, encaminados a probar la relevancia decisiva de la medicina en la configuración de las leyes, la administración del Estado, la organización de la educación o incluso la elaboración y depuración de los preceptos morales. Así, se publicaron diversas obras -como los Pensamientos sobre la razón de las leyes derivada de las ciencias físicas (1810) de Ramón López Mateos o la Filosofía de la legislación natural fundada en la antropología (1838) de Francisco Fabra y Soldevila- que, muy influidas por Les lois eclairées par les sciences physiques (1798) de F.M. Foderé, pontificaban de forma reiterada sobre la «necesidad de buscar las bases o principios de las leyes sociales, no en lo arbitrario de la historia o en lo vago de las especulaciones abstractas, sino en los conocimientos de la naturaleza del hombre» ${ }^{48}$. Es importante añadir que, en su afán por consolidar la proyección pública de su experticia, estos médicos no se abstenían de expresar todo tipo de apreciaciones sobre cuestiones políticas y de buen gobierno, pues, como indicaba Varela de Montes,

«si bajo el imperio de la sociedad y de sus costumbres se halla el poder de pervertir un sano organismo, ¿por qué bajo la influencia de un buen gobierno y

46 Delgrás, Mariano, «La importancia político-social del médico», Boletín de Medicina, Cirugía y Farmacia, 1, 2S (1840), págs. 261-264, pág. 263.

47 Sobre esta obra, que gozó de cierto renombre en la época, véase ARQUIOLA, Elvira, «La incorporación a España de una visión utópica de la medicina: El Ensayo de Antropología de Varela de Montes (1796-1868)», en: ARQuiola, Elvira y MARTÍNEZ-PÉREZ, José, Ciencia en expansión: Estudios sobre la difusión de las ideas científicas y médicas en España (siglos XVIII-XX), Madrid, Editorial Complutense, 1995, págs. 105-119. Sobre la producción explícitamente «antropológica» de los médicos españoles en las décadas centrales del siglo XIX, véase CARreras Y ARTAU, Tomás, Estudios sobre médicos-filósofos españoles del siglo XIX, Barcelona, CSIC, 1952, págs. 43-50; y RONZÓN, Elena, Antropología y antropologías: Ideas para una historia crítica de la antropología española. El siglo XIX, Oviedo, Pentalfa-El Basilisco, 1991, págs. 171-251. Por su parte, la bibliografía sobre el desarrollo de la higiene en la España del siglo XIX es muy abundante. Una revisión reciente centrada en el análisis biográfico de algunas de sus figuras más destacadas se ofrece en CAMPOS, Ricardo, Monlau, Rubio, Giné. Curar y gobernar: Medicina y liberalismo en la España del siglo XIX, Madrid, Nívola, 2003.

48 FABRA Y SOlDevila, Francisco, Filosofía de la legislación natural fundada en la antropología, Madrid, Imprenta del Colegio de Sordomudos, 1838, pág. XXV. 
de una buena sociedad no ha de existir el poder de conservarlo y aun de mejorar física e intelectualmente el género humano?»49.

En consecuencia, del mismo modo que sólo el conocimiento del hombre estaba en condiciones de fundar un orden político verdaderamente justo, la bondad o la iniquidad de los gobiernos debía juzgarse atendiendo, sobre todo, a sus efectos sobre la salud. Para Frau, por ejemplo, era más que evidente que, así como:

«las desgracias, las revoluciones y los trastornos de las naciones y de los imperios, presentes y pasados, han tenido por principal causa, cuando no por única, la inobservancia de las leyes y de los preceptos emanados naturalmente del estudio filosófico del hombre, [...] sólo los Gobiernos monárquico-representativos, permitiendo al individuo la libre expresión del pensamiento, asegurando su persona y bienes y los derechos civiles y políticos que le competan, hasta el punto de tener tranquilo su espíritu y no dar lugar a combates ni agitaciones interiores, mantendrán tranquilo al Estado»50.

Otros focos de interés y reivindicación constante por parte de los médicos fueron, como ya se ha señalado, la educación y la moral. Desde la extensa memoria sobre «La educación viciosa, física y moral en la niñez» presentada en 1817 por el licenciado José Cansino ante la Real Sociedad de Sevilla al Ensayo sobre la perfección del hombre en la extensión de su ser (1842) de José Jorge de la Peña, el género pedagógico, cultivado en ocasiones con fuertes resonancias rousseaunianas, empezó a tener una presencia notable en la cultura médica española. Por un lado, la importancia de la educación para el médico estaba fuera de toda duda, pues, como apuntaba De la Peña, «todo está sujeto a su influencia, y nada hay, ni en el mundo físico, ni en el intelectual, que no sea capaz de ejercer una acción, sea la que fuere, en la economía viva» ${ }^{51}$. Pero, además, muchos médicos opinaban que la dimensión antropológica de su ciencia les erigía de forma natural en los actores más cualificados para regir los destinos de la educación en un sentido amplio: «Los estudios médicos —clamaba un doctorando de la Universidad Central en 1854- son necesarios para la dirección de la humanidad, y sin ellos el desarrollo físico, intelectual y moral del hombre nunca alcanzará su perfección» ${ }^{52}$. Por su parte, las supuestas relaciones de la higiene o la medicina con la moral fueron objeto de planteamientos muy similares. En la estela de las preocupaciones morales de los Ideólogos y otros médicos

49 VARela de Montes, José, Ensayo de antropología o sea historia fisiológica del hombre, vol. 4 , Madrid, Bailly-Baillière, 1845, pág. 370.

50 FRAU y ARMENDÁrIZ, Ramón, La medicina es..., págs. 7 y 12.

51 De La PeÑa, José Jorge, Ensayo sobre la perfección del hombre en la extensión de su ser, Madrid, Imprenta del Colegio Nacional de Sordomudos, 1842, pág. 5.

52 CAmpello y ANTÓN, Francisco, Importancia de la medicina en el desarrollo físico, intelectual y moral del hombre, Madrid, Imprenta del Colegio de Sordomudos y de Ciegos, 1854, pág. 23. 
franceses ${ }^{53}$, los médicos españoles insistieron en el discurso tradicional sobre la importancia de las costumbres o la virtud en el mantenimiento de la salud, si bien tendieron a añadirle un sesgo utilitario muy característico del pensamiento del siglo XIX. Así, mientras Vendrell de Pedralbes sostenía que «mirándolo bien, la medicina demuestra que debemos ser buenos por cálculo exacto», Frau explicaba que:

«como la higiene y la moral se hallan tan hermanadas que puede decirse que guardan entre sí la misma relación que el físico con lo moral del hombre, resulta que los preceptos higiénicos son al mismo tiempo morales; y por consiguiente indirectamente pueden moralizarse los hombres, aprovechando las reglas de una sabia higiene cuya observancia les interesa tan de cerca»54.

Fuera o no justificada con argumentos fisiológicos, esta ecuación entre higiene y moral se convirtió en un lugar común en las décadas centrales del siglo, hasta el punto de constituir el tema preferente de numerosos opúsculos o disertaciones en las que se situaban a ambas en el marco de un mismo orden natural sancionado tanto por la ciencia como por la religión ${ }^{55}$. Resulta ocioso añadir aquí que lo que se había iniciado como un intento explícito de medicalizar la moral terminó entonces en una asombrosa moralización de la medicina misma; y este hecho, sobre el que habrá que volver más adelante, representa no tanto un anacronismo momentáneo o específicamente español en el largo camino hacia una objetividad médica cada vez más depurada, sino que es muy revelador del papel esencialmente normativo asumido por la ciencia y la medicina en el seno de la nueva sociedad burguesa ${ }^{56}$.

En este sentido, una buena forma de apreciar la ambición totalizadora, el carácter utópico y las fuertes tendencias normativas de la medicina decimonónica española es atender al retrato intensamente idealizado que los médicos solían hacer de sí mismos en relación con su saber, su proyección sociopolítica o

53 Véase JACYNA, L.S., "Medical science and moral science: The cultural relations of physiology in Restoration France", History of Science, 25 (1987), págs. 111-146.

54 Pedralbes, José Francisco, Influxo de las costumbres..., pág. 20; y FraU Y Armendáriz, Ramón, La medicina es..., págs. 22-23.

55 Algunos ejemplos de este género son Alonso Lasso De La Vega, Luciano, Armonía de la bigiene con la moral, Madrid, Imprenta de Antonio Martínez, 1854; PUSALGAS y GuERRIS, Ignacio M. ${ }^{a}$, Discurso sobre la religión, la moral y la bigiene como inseparables hermanas que de consuno procuran la felicidad del hombre, Madrid, Imprenta de F. Sánchez, 1857; o RODRíGUEZ CarreÑo, Manuel, «Estudios filosóficos y morales de higiene pública y privada», El Siglo Médico, 10-11 (1863-64).

56 Véanse, para el caso español, los siguientes estudios: CAMPOS, Ricardo, «La sociedad enferma: Higiene y moral en España en la segunda mitad del siglo XIX y principios del XX», Hispania, 55 (1995), págs. 1093-1112; GONZÁLEZ DE PABLO, Ángel, «Sobre la configuración del modelo de pensamiento de la higiene actual: El caso español», Dynamis, 15 (1995), págs. 267-299; y Huertas, Rafael, Los laboratorios de la norma: Medicina y regulación social en el Estado liberal, Barcelona, Octaedro, 2008. 
sus cualidades morales. Siguiendo las pautas establecidas por Alibert o Gregory ${ }^{57}$, los discursos sobre los «deberes, cualidades y conocimientos del médico» o sobre «moral médica», muy populares en la época, abundan en descripciones totalmente inflacionarias del saber y las atribuciones del médico, pero destacan especialmente por su desmedido énfasis en la dimensión moral de su quehacer. En un texto muy representativo del género, el catedrático barcelonés Félix Janer no vacilaba en exclamar «iCuántas virtudes religiosas y naturales practican el médico y el cirujano en el exacto cumplimiento de las muchas y diferentes obligaciones que les impone su profesión!»; y pasaba a explicitar éstas en una lista que no admitía fisuras:

«religión, templanza y sobriedad; circunspección y decencia; serenidad, valor y firmeza de carácter; afición al estudio y a la observación; capacidad de dudar en ciertos casos; humanidad, afabilidad y cortesanía (sic); gravedad y entereza; candor y veracidad; prudencia; secreto; desinterés; fortuna; confianza»58.

El ya citado Vendrell de Pedralbes, por su parte, llegaba incluso a prescribir una suerte de proceso ascético para el ejercicio de la medicina, tras el cual, «libre el médico de la tiranía de las pasiones, sea dulce, tranquilo, amable, honesto, generoso; y obre siempre con madura reflexión, con equidad y con justicia» $\$$.

Como hemos visto, pues, las múltiples consecuencias y derivaciones del programa antropológico de la medicina posrevolucionaria francesa y europea se hicieron sentir con fuerza también en España, provocando una transformación sin precedentes en la percepción de la medicina y de su lugar en la sociedad. En lo que aquí interesa, una de las implicaciones más significativas de este programa fue, sin duda, la pretensión de los médicos de tomar como objeto al ser humano en su totalidad, esto es, no sólo al cuerpo o al «hombre físico», sino también — como se decía entonces—al «hombre intelectual y moral». A esto contribuyeron inicialmente los planteamientos organicistas de algunas escuelas o el recurso a una serie de nuevos conceptos fisiológicos (sensibilidad, organización, economía animal, etc.), si bien la consideración del psiquismo como un ámbito particularmente relevante para la medicina o, dicho en otros términos, la introducción del «sujeto psicológico» como un blanco destacado de la intervención del médico, progresaron incluso sin ellos. Así, de acuerdo con el céle-

57 Cf. Alibert, Jean Louis, Discurso sobre la conexión de la medicina...; y GreGORY, John, Discurso sobre los deberes, qualidades y conocimientos del médico, con el método de su estudio, Madrid, Imprenta Real, 1803.

58 JANER, Félix, Elementos de moral médica o tratado de las obligaciones del médico y del cirujano, Barcelona, Imprenta de Joaquín Verdaguer, 1831, págs. 5 y 54-163.

59 Pedralbes, José Francisco, Influxo de las costumbres..., pág. 41. Véase también, en esta misma línea, BUSTO y LÓPEZ, Andrés del, Discurso sobre el sacerdocio médico considerado en su estudio y ejercicio, Madrid, Imprenta de Aguado, 1853. 
bre aforismo del médico alemán J.G. Zimmermann según el cual «quien no sea capaz de observar al hombre moral, jamás conocerá las enfermedades del cuerpo» ${ }^{60}$, el siglo XIX asistió a una verdadera eclosión de los contenidos psicológicos entre las inquietudes teóricas de los médicos españoles, y este proceso encontró su articulación más definida en el paulatino despliegue de un discurso que, aunque centrado todavía en el viejo tópico de las pasiones, allanaría el camino para la implantación posterior de las modernas ciencias de la mente.

\section{LA MEDICINA DE LAS PASIONES}

El tránsito del siglo XVIII al XIX asistió, como se ha dicho, a una creciente preocupación por los efectos de las pasiones sobre la salud y la enfermedad en la cultura médica europea, hasta el punto de que los médicos empezaron a reivindicarlas como una cuestión más propia de sus competencias que de las de los filósofos o los moralistas. Ciertamente, las razones de este interés han de buscarse tanto en la progresiva difusión del ideario naturalista de la ciencia ilustrada como en el énfasis en la dimensión afectiva e irracional del ser humano alentado por el despertar de la conciencia romántica ${ }^{61}$; pero la prominencia cultural de las pasiones - y su apropiación discursiva por parte de los médicos- han de verse también en el marco del nuevo contexto sociopolítico surgido de las convulsiones revolucionarias de la época. De forma análoga a la imaginación, su potencial perturbador se convirtió, de hecho, en todo un símbolo de la fragilidad del psiquismo para afrontar las exigencias normativas de la nueva sociedad burguesa, y, conforme al nuevo rol otorgado a la ciencia, la medicina parecía ofrecer las mayores garantías para revertir o modular su acción sobre el orden moral de los individuos o las naciones ${ }^{62}$. Alibert, por ejemplo, no vacilaba en recurrir a un tono grave y trágico para reivindicar enfáticamente el «estudio médico del corazón humano», pues, tal como decía, «¿qué es al fin la vida, sino un mar siempre borrascoso con los descerrajados vientos de las pasiones y de la adversidad?... Y, para sacarnos de tantos naufragios, iqué inmensidad de exquisitos recursos no son menester!» ${ }^{63}$.

Siempre a remolque de las ideas francesas, en España se tuvo cumplida noticia de todo este discurso médico-psicológico en torno a las pasiones merced a las reseñas o las traducciones de obras emblemáticas como la ya citada de Tissot (1798), la Fisiología de las pasiones (1826) del propio Alibert ${ }^{64}$. En cualquier

60 Citado por Carreras y Artau, Tomás, Médicos-filósofos..., págs. 29-30.

${ }_{61}$ Cf. GuSDORF, Georges, Naissance de la conscience romantique au siècle des lumières, París, Payot, 1976, págs. 82-123.

62 Véase, en este sentido, Goldstein, Jan, The Post-Revolutionary Self: Politics and psyche in France, 1750-1850, Cambridge MA, Harvard University Press, 2005, págs. 19-100.

63 ALIBERT, Jean Louis, Discurso sobre la conexión de la medicina..., pág. 96.

64 A éstas habría que añadir la difusión de las obras de los primeros alienistas (Pinel en 1804, Esquirol en 1847) o de diversos tratados de higiene con un amplio tratamiento de las pasiones como 
caso, el texto más representativo del género, y el que llegaría a convertirse en el compendio canónico y en la mayor fuente de inspiración para los médicos españoles, fue, sin lugar a dudas, La medicina de las pasiones (1842) de J.B.F. Descuret (1795-1871). A pesar de su notable influencia durante buena parte del siglo XIX ${ }^{65}$, de haber sido considerado como uno de los más distinguidos «médicos moralistas» de su tiempo ${ }^{66}$ o de habérsele identificado incluso como un notable precursor de la medicina psicosomática ${ }^{67}$, la figura de Descuret es poco conocida y ha sido, por lo general, muy poco estudiada. Doctor en medicina y en letras, facultativo de los servicios parisinos de beneficencia, gran conocedor de la literatura clásica y ferviente católico, Descuret se propuso ofrecer una "gramática de las pasiones» en completa sintonía con el tono y los esquemas consagrados por los moralistas cristianos, pero, basándose en su larga experiencia clínica y forense, también quiso elaborar «una obra más científica que literaria, y en gran parte copiada al natural» ${ }^{68}$. De este modo, La medicina de las pasiones puede leerse como un singular testimonio de las preocupaciones morales y psicológicas de los médicos europeos y españoles en las décadas centrales del siglo XIX, destacando justamente por su peculiar conjunción de elementos tradicionales -propios de la «dietética del espíritu» de origen clásico o del catolicismo más rancio- y de presupuestos teóricos y metodológicos más «modernos».

Entre estos hay que mencionar, en primer lugar, su desmedida insistencia en atribuir a la influencia orgánica de las pasiones la producción directa de las más diversas enfermedades, asumiendo una noción de psicogenia ciertamente inflacionaria, pero muy pertinente para avalar la medicalización de los fenómenos morales. Para Descuret, era de la máxima evidencia que «las enfermedades producidas por las pasiones son incomparablemente más frecuentes que todas las que dependen de las demás modificaciones de la economía», y no dudaba en afirmar, por ejemplo, que «la mitad de las tisis reconocen por causa el amor o el libertinaje» o que «de 100 tumores cancerosos, 90 al menos deben su principio a afecciones morales tristes» ${ }^{69}$. Por lo que respecta a los médicos españoles, es difícil encontrar en todo el siglo XIX una idea más repetida y popular, que

el ya citado de Pressavin (1800), el Compendio de higiene pública y privada (1829-30) de Léopold Deslandes o el Manual de higiene (1845) de François Foy.

65 La medicina de las pasiones, publicada originalmente en París en 1841 y con reediciones en 1844 y 1860, fue traducida rápidamente a varios idiomas como el español, el italiano y el sueco, y fue también ampliamente conocida en Inglaterra y en Alemania. La versión española, debida a Monlau, tuvo un total de tres ediciones (1842, 1849 y 1857), y se convirtió en una lectura obligada para los médicos y las clases instruidas.

66 Véase, por ejemplo, WoIllEZ, Cathérine T., Les médecins moralistes, París, G. Baillière, 1862.

67 Cf. De Saussure, Raymond, "J.B. Felix Descuret", Psychoanalytic Study of the Child, 2 (1946), págs. 417-424.

68 DeSCuRET, Jean-Baptiste Félix, La medicina de las pasiones, o las pasiones consideradas con respecto a las enfermedades, las leyes y la religión, Barcelona, Imprenta de Antonio Bergnes y C. ${ }^{\text {a }}, 1842$, págs. V-VI.

69 Descuret, Jean-Baptiste Félix, La medicina de las pasiones..., pág. 91. 
se convirtió en todo un lugar común de la cultura médica y en el tema recurrente de innumerables discursos, memorias o tesis doctorales ${ }^{70}$.

En segundo lugar, aunque Descuret no justificaba la naturaleza, las causas, el asiento o la acción de las pasiones apelando a planteamientos estrictamente organicistas, sí creía en la necesidad de examinar empíricamente su epidemiología, sus orígenes fisiológicos, sus correlatos somáticos o su semiología clínica. Por ese motivo, su libro incluye una gran cantidad de datos estadísticos de todo tipo, así como sendas secciones en las que propone una división de las pasiones basada en un concepto de «necesidad biológica» cercano al de instinto, discute la necesaria participación del sistema nervioso en su dinamismo o refiere con gran detalle sus síntomas diferenciales y sus diversos signos fisiognómicos y frenológicos ${ }^{71}$. Y, nuevamente, también estos puntos de vista fueron ampliamente secundados por los médicos españoles, que adoptaron de forma mayoritaria el esquema clasificatorio de las pasiones propuesto por Descuret ${ }^{72}$, reivindicaron puntualmente la importancia de su estudio fisiológico y mostraron, debido sin duda a sus implicaciones médico-legales, un interés particular por su semiología y su diagnóstico diferencial con la monomanía o la locura ${ }^{73}$.

70 Tal y como se desprende de la extensa lista de trabajos que he podido localizar y consultar: PERAY y TINTONER, Laureano, Influencia de las pasiones en la producción de las enfermedades, Madrid, Imprenta de D.A. Cubas, 1850; IGLESIAS, Santiago, Discurso sobre la influencia de las pasiones en la producción de las enfermedades, Madrid, Imprenta de Norberto Llorenci, 1853; CanO GonZÁLEZ, Domingo, Influencia ejercida por las pasiones sobre los fenómenos orgánicos del hombre, Madrid, Imprenta de J. M. ${ }^{a}$ Ducazcal, 1854; CASAs De BATiSTa, Eusebio R., Influencia de las pasiones en la producción de las enfermedades, Madrid, Imprenta de Tomás Fortanet, 1859; Fossi y MiQueO, Ramón, Influencia de las pasiones en la producción de las enfermedades, Madrid, Imprenta de J.M. ${ }^{a}$ Ducazcal, 1861; Coloma Y MichelenA, Vitalio de, Influencia de las pasiones en la producción de las enfermedades, Madrid, Imprenta de la Revista de Legislación, 1863; APARICIO Y GARCíA, José, Influencia de las pasiones en la producción de las enfermedades, Madrid, Imprenta de Manuel Tello, 1864; GutiérReZ DEL CorTIJO Y RoIZ, Juan M., Influencia de las pasiones en la producción de las enfermedades, Madrid, Imprenta de A. Peñuelas, 1864; CASTElo y SERRA, Eusebio, De la influencia de las pasiones en la producción de las enfermedades, Madrid, Imprenta de Segundo Martínez, 1868; y Jover, Antonio, De la influencia de las pasiones en el organismo, Barcelona, Imprenta de Jaime Jepús, 1877. En la Biblioteca de la Real Academia Nacional de Medicina de Madrid se conservan, además, las siguientes memorias manuscritas: EsCALADA, Gregorio, Influencia de las pasiones en el físico del hombre y medios de moderarlas, Madrid, 1830; GONZÁLEZ ZORRILLA, José, Influencia de lo moral en lo físico del hombre, Medina del Campo, 1845; y HeRNÁNDEZ Y GuASCO, Andrés, Memoria sobre la influencia de las pasiones en la economía animal, Mahón, 1850. CARreras y ARTAu, Tomás, Médicos-filósofos..., págs. 27-28, menciona, por su parte, la existencia de otras tres memorias presentadas a la Real Academia de Medicina de Barcelona entre 1800 y 1855.

71 Cf. Descuret, Jean-Baptiste Félix, La medicina de las pasiones..., págs. 6-16, 16-20, 20-68, 69-85 y $142-160$.

72 Aparte de los trabajos listados en la nota 70, véanse si no Monlau, Pedro F., Elementos de bigiene privada..., págs. 365-413; Monlau, Pedro F., Elementos de higiene pública, Barcelona, imprenta de D. Pablo Riera, 1847, págs. 723-820 o GINÉ y PARTAGás, Juan, Curso elemental de bigiene..., págs. 484-496.

73 Los escritos médicos dedicados a estas cuestiones fueron, de hecho, muy numerosos en las décadas centrales del siglo XIX. Entre ellos, cabe destacar QUINTANA, Joaquín, «Pasión y locura: 
Por último, y a pesar de que sus observaciones terapéuticas se situaban todavía en el marco dietético clásico basado en el manejo de las «cosas no naturales», Descuret era también partidario de fomentar entre los médicos el recurso sistemático a los «remedios morales», y compiló una apreciable casuística sobre la aplicación de rudimentarias técnicas psicológicas encaminadas a manipular, distraer, antagonizar o incluso aprovechar los efectos beneficiosos de las pasiones ${ }^{74}$.

«Entiendo — concluía- que la medicina moderna no da la suficiente importancia al tratamiento de las enfermedades causadas o sostenidas por las pasiones. ¿Qué lástima! Se ven todos los días prácticos distinguidos formular exclusivamente prescripciones farmacéuticas en casos que ante todo reclaman remedios morales»75.

En España, por su parte, las referencias de este tipo al «tratamiento moral» de las enfermedades, presentes desde finales del siglo XVIII, fueron muy abundantes en las décadas centrales del siglo XIX, y no se limitaron a la recepción de la tecnología más o menos específica diseñada por los alienistas, sino que remitían a menudo al conjunto de la medicina clínica ${ }^{76}$. En síntesis, pues, puede decirse que en la obra de Descuret y, en un sentido más amplio, en la cultura médica europea y española de mediados del siglo XIX, es posible localizar — si bien todavía de una forma embrionaria - toda una serie de elementos muy característicos de las modernas ciencias de la mente (como la idea de psicogenia, el énfasis en la investigación fisiológica, la aplicación de la estadística, la elaboración de una semiología del psiquismo o el desarrollo de tratamien-

Distinción fundamental entre ambos estados», El Siglo Médico, 10 (1863), págs. 212-215, 227-230 y 244-247; y MATA, Pedro, Criterio médico-psicológico para el diagnóstico diferencial de la pasión y la locura, Madrid, Imprenta de R. Berenguillo, 1868. En las décadas de 1860 y 1870 se presentaron, además, varias decenas de tesis doctorales en la Universidad Central sobre los «caracteres diferenciales de la monomanía y la pasión». Cf. GARCíA, Emilio y ALONSO, Aurora, «Enfermedad mental y monomanía: Estudio de tesis doctorales en España (1850-1864)», Revista de Historia de la Psicología, 22 (2001), págs. 335-342.

74 «Venenos hay - decía- que, en las manos de un hábil facultativo, se convierten diariamente en remedios eficaces» (DescurET, Jean-Baptiste Félix, La medicina de las pasiones..., pág. 123). Sobre esta tradición, véase JACKSON, Stanley W., "The use of the passions in psychological healing", Journal of the History of Medicine and Allied Sciences, 45 (1990), págs. 150-175.

75 Descuret, Jean-Baptiste Félix, La medicina de las pasiones..., pág. 95.

76 Véanse, por ejemplo, los siguientes trabajos: GonZÁLez Y CentenO, Valentín, «Las enfermedades que proceden de pasión de ánimo, no son curables con remedios naturales», Memorias académicas de la Real Sociedad de Medicina y demás Ciencias de Sevilla, 4 (1786), págs. 1-19; S.D., «Terapéutica moral: Influjo de las pasiones consideradas como medio terapéutico en la curación de las enfermedades», Boletín de Medicina, Cirugía y Farmacia, 4, 2S (1843), págs. 201-203; F.A., «Del tratamiento moral de las enfermedades», Gaceta Médica, 7 (1851), págs. 57-58; LuCIA, Carlos, «Ligeras consideraciones sobre la importancia de conocer el estado moral y el genio particular de los enfermos para la mejor dirección de sus dolencias», Boletín de Medicina, Cirugía y Farmacia, 3, 2S (1853), págs. 369-370. 
tos psicológicos), de manera que la «medicina de las pasiones» decimonónica bien puede considerarse como un importante (y poco atendido) eslabón en la constitución histórica de las mismas.

En cualquier caso, interesándose por las pasiones, la intención de Descuret (y de una mayoría de los médicos de su tiempo) era, ante todo, moralizar, o, como él mismo decía, «auxiliar a la moral en la grandiosa obra de mejorar la suerte de los hombres» ${ }^{77}$. En este punto, además, sus planteamientos no podían resultar más conservadores, alineándose en las filas de una corriente de regeneración religiosa y social que inspiró a numerosos médicos de la época y contribuyó, sin duda, a que su obra fuera tan popular en países como España o Ita$\operatorname{lia}^{78}$. Así, Descuret asimilaba en todo momento las pasiones, «esos pérfidos y formidables enemigos de nuestro reposo», al pecado, el vicio y el exceso, y su «fatal tiranía» no era para él sino la expresión más certera de la trágica e impura condición del hombre, "una inteligencia caída en lucha incesante con los órganos» ${ }^{79}$. En su opinión, los «mismos progresos de la civilización», sobrexcitando «las pasiones instintivas y brutales en las masas» y debilitando las instancias sociales destinadas a contenerlas ${ }^{80}$, estaban convirtiendo esa lucha en una lid cada vez más compleja, difícil e incierta. Y, en consecuencia, reclamaba simultáneamente el concurso de la medicina en la reforma de las costumbres de las naciones y el de la religión en el tratamiento moral de los individuos, pues

77 DescurEt, Jean-Baptiste Félix, La medicina de las pasiones..., pág. III.

78 De hecho, La medicina de las pasiones ha de encuadrarse en un género de abierta inspiración religiosa que tuvo una fuerte influencia en la medicina francesa y española de las décadas centrales del siglo XIX. Otras obras destacadas de esta corriente también traducidas en España fueron De la fisiología humana y medicina en sus relaciones con la religión cristiana, la moral y la sociedad (1843) de François Devay o los Pensamientos de un creyente católico, o consideraciones filosóficas, morales y religiosas sobre el materialismo moderno, el alma de las bestias, la frenología, el suicidio, el duelo y el magnetismo animal (1849) de Pierre-Jean-Corneille Debreyne. Véase, en una línea muy similar, SAN MARTín, Basilio, «Discurso preliminar a la higiene de las pasiones», La Crónica de los Hospitales, 2 (1854), págs. 428435 y $494-502$.

79 Descuret, Jean-Baptiste Félix, La medicina de las pasiones..., pág. IX (cursivas en el original). De este modo, la lista de pasiones particulares estudiada por Descuret incluía de forma preferente los pecados capitales del cristianismo, así como conductas muy reprobadas por la moral tradicional como el suicidio, la ebriedad o la afición al juego.

80 Descuret, Jean-Baptiste Félix, La medicina de las pasiones..., pág. 99. «Estudiada bajo este punto de vista — proseguía Descuret—, la Europa presenta a los observadores alarmantes síntomas de una disolución próxima e inevitable, si el cristianismo no viene a obrar una regeneración saludable». En una línea muy similar, una tesis doctoral presentada en 1856 en la Universidad Central alertaba de forma enfática sobre la peligrosidad social de diversos fenómenos de la vida moderna como la ociosidad, el pauperismo, la incredulidad, el periodismo o incluso los dramas teatrales: «El teatro, en dramas de este género, se convierte en terreno que abrasa. Si fuera dado a la medicina penetrar en los pliegues del alma, la prohibición de estas emociones se elevaría a axioma para la curación de muchas enfermedades» (CARRERAS Y XURIACH, José, Influencia social en las pasiones, Madrid, Imprenta de Eusebio Aguado, 1856, pág. 20). 
«iqué freno más poderoso, qué remedio más eficaz para contener la violencia de las pasiones, que la obligación de dar cuenta de todas nuestras faltas a Dios!»81.

La obra de Descuret, en suma, ha de entenderse como un singular compendio en el que se insinúan de forma tentativa métodos y presupuestos de la medicina moderna, pero cuyo espíritu se halla completamente al servicio de la estabilización de un determinado orden moral que se pretende armónicamente derivado de la ciencia y la religión. En ese sentido, su aportación resulta paradigmática no sólo de la evolución de un género que había interesado a los médicos desde la Antigüedad, sino también de una época en la que la medicina, como decía uno de sus epígonos franceses, entró en una «juiciosa alianza con la moral» con el objeto de garantizar «el cumplimiento de la ley de la naturaleza, la justa moderación en todas las cosas y la satisfacción armónica de todas nuestras necesidades ${ }^{82}$. No en vano, el mismo blanco y objeto de todo este discurso médico era el concepto ancestral de las pasiones, cuya misma naturaleza era por definición moral y que, como han mostrado diversos autores, sólo pudo conducir a la categoría contemporánea (menos conductual, más fenomenológica y axiológicamente neutra) de las emociones tras un largo y complejo proceso de secularización de los contenidos psicológicos ${ }^{83}$.

\section{DEL ALMA A LA MENTE}

Desde este punto de vista, pues, la copiosa literatura médica del siglo XIX en torno a las pasiones aparece como un producto de transición cuyas reminiscencias tradicionales han impedido quizá una justa valoración de su singularidad, pero, sobre todo, de su condición de escenario privilegiado en el que se dirimió la paulatina pero imparable medicalización del psiquismo que, para el caso español, hemos venido analizando en este artículo. En 1807, el ya citado Diccionario de Antonio Ballano concluía su entrada (anónima) sobre las pasiones con la siguiente reflexión:

«Esta materia nos ofrece ciertamente un campo vastísimo para hacer aplicaciones a la higiene, a la política y a la medicina práctica. [...] Para conocer y aprovecharse del influjo de las pasiones, el médico debe dedicarse con particulari-

81 Descuret, Jean-Baptiste Félix, La medicina de las pasiones..., pág. 120. Descuret, de hecho, llegó a incluir en La medicina de las pasiones una sección dedicada al «Tratamiento religioso» de las mismas (págs. 119-122).

82 BOURGEOIs, Louis-Xavier, Les passions dans leurs rapports avec la santé et les maladies: L'amour, París, J.B. Baillière, 1860 (edición española de 1878), págs. 6 y 36.

83 Proceso que, como certifican las conocidas publicaciones sobre las emociones de Charles Darwin o William James, sólo pudo completarse a lo largo de la segunda mitad del siglo XIX. Véase RORTY, Amelie O., "From passions to emotions and sentiments", Philosophy, 57 (1982), págs. 175-188; y sobre todo DiXON, Thomas M., From Passions to Emotions: The creation of a secular psychological cathegory, Cambridge, Cambridge University Press, 2003. 
dad a la filosofía de su arte, esto es, al doble conocimiento del hombre moral y del hombre físico. [Pero] dejemos a la moral el cargo de dirigir las pasiones, y a la metafísica el de analizarlas» ${ }^{84}$.

Del mismo modo, en una memoria manuscrita sobre la Influencia de las pasiones en el físico del hombre remitida 1830 a la Real Academia Nacional de Medicina de Madrid, el candidato Gregorio Escalada valoraba su competencia en unos términos muy similares:

«Parecerá sin duda inoportuno el pretender dar reglas para dirigir las pasiones del hombre, ni menos analizarlas, en un discurso médico, puntos que al parecer corresponden a la moral y a la metafísica, mas como la medicina tiene tantos puntos de contacto con las demás ciencias auxiliares y somos de ordinario consultados sobre tales asuntos de higiene pública, he creído mi deber recorrer semejantes cuestiones» 85 .

Sólo unas décadas después, el médico Balbino Quesada, muy influido por Descuret y el idealismo krausista, situaba ya sus Estudios médico-morales y sociales sobre las pasiones en el ámbito explícito de una «medicina moral», a la que definía solemnemente como «un caudal inmenso de sazonados consejos y saludables advertencias, y faro luminoso que ha de guiarnos para dirigir con acierto la nave de nuestra existencia en el mar proceloso de la vida terrena» ${ }^{86}$. Y, como hemos visto, no fue necesario esperar mucho para que Céspedes repudiara el «aéreo edificio levantado por filósofos y moralistas» reclamando un estudio «fisiológico descriptivo» de las pasiones, o Giné proclamara la «conquista del mundo psicológico» por parte de la medicina en el ejercicio de su legítimo «derecho como ciencia biológica, experimental y curativa».

Paradójicamente, como hoy sabemos, la misma ambición de la ciencia positivista de fundar un conocimiento del psiquismo en tercera persona, objetivo y basado en categorías exentas de consideraciones morales ${ }^{87}$, fue la que acabó con el uso científico del concepto mismo en el que, como nuevo saber del hombre, la medicina centró durante décadas su asedio a los territorios del «mundo moral». Y por eso la mente, esa mente secular que desde el siglo XIX estudiamos en sus enfermedades, en sus estructuras orgánicas o en sus funciones es, ella

84 Ballano, Antonio (dir.), Diccionario de medicina y cirugía o biblioteca manual médico-práctica, vol. 6, N-R, Madrid, Imprenta Real, 1805, págs. 194 y 199.

85 ESCALADA, Gregorio, Influencia de las pasiones..., pág. 2.

86 QuesADA, Balbino, Estudios médico-morales y sociales sobre las pasiones, Úbeda, Imprenta de Juan José Górriz, 1868, pág. 7.

87 Véanse, en este sentido, GoldsteIn, Jan, "Bringing the psyche into scientific focus", en: The Cambridge History of Science, vol. 7: The Modern Social Sciences, Cambridge, Cambridge University Press, 2003, págs. 131-153; y DASTON, Lorraine y GALISON, Peter, Objectivity, Nueva York, Zone Books, 2007, págs. 191-251; así como las obras citadas en las notas 4, 5 y 20. 
misma, el resultado de una determinada manera de ver al ser humano cuya emergencia histórica tanto debe al progresivo despliegue de la ciencia moderna.

Recibido: 07-10-2009

Aceptado: 06-09-2010 